\title{
Sergančiųjų nekontroliuojama astma gydymas itin smulkių dalelių trijų vaistų deriniu viename inhaliatoriuje: TRIMARAN ir TRIGGER tyrimai
}

\author{
SINGLE INHALER EXTRAFINE TRIPLE THERAPY IN UNCONTROLLED ASTHMA: \\ TRIMARAN AND TRIGGER TRIALS
}

KRISTINA BIEKŠIENĖ

LSMU MA Pulmonologijos klinika

\begin{abstract}
Santrauka. Iki šiol nebuvo atlikta tyrimų, vertinusių trijų vaistų derinio viename inhaliatoriuje veiksmingumą gydant sergančiuosius astma. Šiame straipsnyje pristatomi du nauji klinikiniai tyrimai, kurie pirmą kartą ịvertino itin smulkių dalelių beklometazono dipropionato (BDP), formaterolio fumarato (FF) ir glikopironio (G) derinio viename inhaliatoriuje veiksmingumą, lyginant su BDP ir FF deriniu, gydant sergančiuosius nekontroliuojama astma. Tyrimų rezultatai parodé, kad sergantiesiems nekontroliuojama astma ir gydomiems įkvepiamaisiais gliukokortikoidais bei ilgo veikimo $\beta_{2}$ agonistais, pridejus ilgo veikimo muskarino antagonistą, pagèrẻja plaučių funkcija bei sumažèjo paūmèjimų dažnis.

Reikšminiai žodžiai: astma, itin smulkios dalelès, triguba terapija, ilgo veikimo muskarino antagonistai.

Summary. To date, no studies have assessed the efficacy of single-inhaler triple therapy in asthma. Two studies that compared the single-inhaler extra-fine combination of beclometasone dipropionate (BDP; inhaled corticosteroid), formoterol fumarate (FF; long-acting $\beta_{2}$ agonist) and glycopyrronium (G; long-acting muscarinic antagonist) with the combination of BDP with FF will be presented in this article. In uncontrolled asthma, adding a long-acting muscarinic antagonist to inhaled corticosteroid plus long-acting $\beta_{2}$ agonist therapy improves lung function and reduces exacerbations.
\end{abstract}

Key words: asthma, extra-fine particles, triple therapy, long-acting muscarinic antagonist.

DOI: https://doi.org/10.37499/PIA.767

\section{IVADAS}

Astma - viena dažniausių lètinių kvėpavimo takų ligų. Gydant astmą, siekiama dviejų pagrindinių tikslų - pasiekti ir išlaikyti simptomų kontrolę bei sumažinti riziką ateityje, ypač paūmèjimų [1]. Astma apibūdinama kaip lètinè uždegiminè kvèpavimo takų liga, o ịkvepiamieji gliukokortikoidai (IGK) yra pagrindiniai kontroliuojamieji vaistai astmai gydyti. Daugeliui pacientų pavyksta pasiekti ligos kontrolę gydant įkvepiamųjų gliukokortikoidų ir ilgo veikimo $\beta_{2}$ agonistų deriniu (IVBA) [2]. Tačiau pasirinkimo galimybių pacientams, kuriems nepavyksta pasiekti astmos kontrolès, gydant šiuo deriniu, yra vos keletas.

Ankščiau atlikti tyrimai parodè, kad sergantiesiems astma, kuriems yra nuolatine kvėpavimo takų obstrukcija ir jie gydomi IGK bei IVBA, pridejus ilgo veikimo muskarino antagonistą tiotropi, pagerèja kvėpavimo funkcija ir, kaip parodè ilgesnès trukmès tyrimai (48 savaičių trukmès), sumažeja paūmejjimų rizika [3-5]. Tačiau, pridejus tiotropi, astma sergantys pacientai turi naudoti du inhaliatorius, kurie yra skirtingo dizaino, naudojimo technikos bei neretai ir skirtingo dozavimo režimo. Toks derinys nèra patogus nei pacientui, nei sveikatos priežiūros specialistui, kuris apmoko inhaliavimo technikos, taip pat tai gali neigiamai paveikti gydymo režimo laikymąsi bei gydymo tęstinumą [6-9].

Itin smulkių dalelių (vidutinis aerodinaminis skersmuo (angl. mass median aerodynamic diameter, MMAD) $<2 \mu \mathrm{m}$ ) triguba terapija viename inhaliatoriuje, susidedanti iš beklometazono dipropionato (BDP), formaterolio fumarato (FF) ir glikopironio $(\mathrm{G})$, yra skiriama per suslègto oro fiksuotų dozių inhaliatorių (angl. pressurized metered dose inhalers, pMDI). Tokia itin smulkių dalelių forma pagerina vaisto nusèdimą smulkiuosiuose kvėpavimo takuose [10], o tai potencialiai svarbu sergantiesiems astma, kuriems yra sutrikusi smulkiųjų kvèpavimo takų funkcija. Šių pacientų astmos kontrolè, gyvenimo kokybẻ būna blogesnè, o paūmèjimų rizika didesnè [11].

Šiame straipsnyje pateikiami du pirmieji tyrimai, kurių metu vertinta itin smulkių dalelių trigubos te- 


\section{Farmakoterapija}

rapijos viename inhaliatoriuje veiksmingumas gydant skirtingus astma sergančius pacientus, t. y. ne tik tuos, kuriems yra nuolatinė kvèpavimo takų obstrukcija. Tyrimai trečios fazès 52 savaičių trukmès: TRIMARAN (angl. Triple in Asthma With Uncontrolled Patients on Medium Strength of ICS $+L A B A)$ - triguba terapija sergantiesiems nekontroliuojama astma ir gydomiems vidutinèmis IGK dozèmis bei IVBA, ir TRIGGER (angl. Triple in Asthma High Strength Versus ICS/ $L A B A$ HS and Tiotropium) - triguba terapija skiriant dideles IGK dozes sergantiesiems astma, lyginant su gydymu didelèmis IGK dozèmis, IVBA ir tiotropiu. Itin smulkių dalelių trigubos terapijos (BDP/FF/G), skiriant vidutines IGK (BDP) dozes TRIMARAN tyrime ir dideles IGK dozes (BDP) TRIGGER tyrime, veiksmingumas ir saugumas buvo lygintas su gydymu dviguba terapija (BDP/FF), skiriant vidutines IGK (BDP) dozes TRIMARAN tyrime ir dideles IGK (BDP) dozes TRIGGER tyrime, gydant pacientus, sergančius nekontroliuojama astma, kurie iki tyrimo buvo gydyti vidutinèmis - didelèmis IGK dozèmis ir IVBA.

\section{TYRIMO DIZAINAS IR DALYVIAI}

TRIMARAN ir TRIGGER - tai du atsitiktinių imčių, paralelinių grupių, dvigubai akli, aktyviai kontroliuoti trečios fazès tyrimai. Pagrindinis skirtumas tarp šiu tyrimų yra IGK dozė, kurią pacientai vartojo iki tyrimo ir tyrimo metu. TRIMARAN tyrime pacientai vartojo vidutines, o TRIGGER - dideles IGK dozes.

TRIMARAN tyrime dalyvavo pacientai iš 16 šalių, 171 tyrimo centro, o TRIGGER tyrime - iš 17 šaliu 221 centro. Tyrimo centrai buvo antrinio ir tretinio lygio sveikatos priežiūros paslaugas teikiantys centrai, specializuoti tyrimų padaliniai. 121 tyrimų centras dalyvavo abiejuose tyrimuose.

Ittraukimo ị tyrimą kriterijai. Pacientai buvo ịtraukti ị tyrimą, jei buvo 18-75 metų amžiaus; astma diagnozuota bent vienerius metus prieš atrankos vizitą ir jaunesniame nei 40 metų amžiuje; forsuoto iškvejpimo tūris per pirmą sekundę (angl. forced expiratory volume in 1 second, $\mathrm{FEV}_{1}$ ) prieš bronchų plètimo mėgini mažesnis nei 80 proc. būtinojo dydžio, o $\mathrm{FEV}_{1}$ pokytis po 10-15 min. po $400 \mu \mathrm{g}$ salbutamolio ịkvejpimo daugiau nei 12 proc. ir daugiau nei $200 \mathrm{ml}$. Kiti ịtraukimo kriterijai: nekontroliuojama astma (Astmos kontrolès klausimynas-7 (angl. Asthma Control Questionnaire-7, ACQ-7) $\geq 1,5$; bent vienas astmos paūmejjimas per pastaruosius 12 mèn., kurio gydymui reikejjo sisiteminių gliukokortikoidų arba vizito į Skubiosios pagalbos skyrių, arba stacionarinio gydymo; taip pat pacientai turejjo vartoti pastovias IGK ir IVBA dozes bent keturias savaites iki tyrimo (TRIMARAN tyrime - vidutines, o TRIGGER - dideles IGK dozes).

Pagrindiniai neįtraukimo ị tyrimą kriterijai. Anamnezeje pacientas buvo gydytas Intensyviosios terapijos skyriuje dèl astmos; sunkus astmos paūmèjimas keturios savaitès iki ịtraukimo ị tyrimą arba ittraukimo metu; bet kokia kita plaučių liga, kuri gali turèti ịtakos tyrimo rezultatams; pacientas rūkorius arba buvęs rūkorius daugiau nei 10 pakmečių, arba metè rūkyti prieš metus ir mažiau iki atrankos vizito; pacientas gydomas monokloniniais antikūniais arba kitais biologiniais vaistais.

\section{TYRIMO PROCEDŪROS}

Pacientai, kurie atitiko įtraukimo ir neturejjo neįtraukimo ị tyrimą kriterijų, atrankos metu turèjo pakeisti astmos gydymą ị itin smulkių dalelių dvigubą terapiją BDP/FF. TRIMARAN tyrime pacientai gydyti $100 \mu \mathrm{g}$ BDP ir $6 \mu \mathrm{g}$ FF, o TRIGGER - $200 \mu \mathrm{g}$ BDP ir $6 \mu \mathrm{g}$ FF po du ikvèpimus du kartus per dieną per pMDI. Toks gydymas skirtas dvi savaites. Pasibaigus dviejų savaičių ìtraukimo laikotarpiui, pacientai buvo atsitiktine

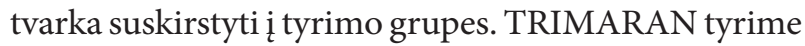
pacientai arba tęsė gydymą BDP/FF tokiomis pačiomis dozèmis, arba gavo itin smulkių dalelių BDP/FF/G, kur $100 \mu \mathrm{g}$ BDP ir $6 \mu \mathrm{g}$ FF, $10 \mu \mathrm{g}$ G, po du îkvèpimus du kartus per dieną per pMDI. TRIGGER tyrime pacientai arba tęsé gydymą BDP/FF tokiomis pačiomis dozèmis po du įkvèpimus du kartus per dieną per pMDI, arba gavo itin smulkių dalelių BDP/FF/G, kuriame $200 \mu \mathrm{g}$ BDP, $6 \mu \mathrm{g}$ FF ir $10 \mu \mathrm{g}$ G, po du i kvejpimus du kartus per dieną per pMDI, arba nekoduojant gavo itin smulkių dalelių BDP/FF, kur $200 \mu \mathrm{g}$ BDP ir $6 \mu \mathrm{g}$ FF po du įkvépimus du kartus per dieną per pMDI ir tiotropi $2,5 \mu \mathrm{g}$ po du ịképimus vieną kartą per dieną per smulkią miglą sukuriantị inhaliatorių (Respimat, Boehringer Ingelheim, Ingelheim am Rhein, Vokietija). Per 52 savaites trukusį tyrimą pacientai vizitui turejo atvykti 4, 12, 26, 40 ir 52 gydymo savaites. Kaip skubiosios pagalbos medikamentą pacientai galejjo vartoti salbutamoli per pMDI.

Gydymo laikotarpiu kiekvieno vizito metu buvo atliekama spirometrija (15 min. prieš vaisto dozę bei 30 min., 1 val., 2 val., ir 3 val. po dozès) ir pildytas ACQ-7. Viso tyrimo metu fiksuoti astmos paūmèjimai. Pacientai taip pat kasdien pildè elektroninius dienynus, kuriuose žymèjo didžiausią iškvėpimo srovę (angl. peak expiratory flow, PEF) ryte ir vakare, astmos simptomus, tyrimo bei skubiosios pagalbos medikamentų vartojimą.

\section{TYRIMUQ VERTINAMOS BAIGTYS}

Pirminè vertinama baigtis buvo rytinio $\mathrm{FEV}_{1}$ prieš vaisto dozę pokytis po 26 gydymo savaičių, lyginant su pradiniu, ir vidutinio sunkumo bei sunkių paūmėjimų dažnis per 52 gydymo savaites. Antrinè vertinama baigtis buvo didžiausio $\mathrm{FEV}_{1}$ ir vidutinio rytinio $\mathrm{PEF}$ pokytis per pirmas 26 gydymo savaites, lyginant su pradiniu, bei sunkių paūmèjimų dažnis. 


\section{Farmakoterapija}

\section{VEIKSMINGUMO IVERTINIMAS}

TRIMARAN tyrime dalyvavo 1155 pacientai, kurie buvo atsitiktinai suskirstyti i BDP/FF/G $(\mathrm{n}=579)$ arba $\mathrm{BDP} / \mathrm{FF}$ grupes $(\mathrm{n}=576)$. TRIGGER tyrime dalyvavo 1437 pacientai, kurie buvo atsitiktinai paskirti i BDP/ FF/G $(\mathrm{n}=573), \mathrm{BDP} / \mathrm{FF}(\mathrm{n}=576)$ arba BDP/FF ir tiotropio grupes $(n=288)$. Pradiniai demografiniai pacientų duomenys tarp penkių grupių nesiskyrè. TRIGGER tyrime pacientų plaučiu funkcijos duome- nys (FEV $\mathrm{F}_{1}$ prieš salbutamolì) buvo kiek blogesni, o grịžtamumas po salbutamolio ịkvèpimo didesnis nei TRIMARAN tyrime (1 lentelè).

Pirminè vertinamoji baigtis, vertinant $\mathrm{FEV}_{1}$ pokyti prieš vaisto dozę po 26 gydymo savaičių, lyginant su pradiniu, buvo pasiekta abiejuose tyrimuose. TRIMARAN tyrime nustatytas reikšmingas $\mathrm{FEV}_{1}$ prieš vaisto dozę pokytis tarp BDP/FF/G ir BDP/FF grupių $57 \mathrm{ml}$ (95 proc. pasikliautinasis intervalas (PI) 15-99;

\section{1 lentelè. Pacientų charakteristikos}

\begin{tabular}{|c|c|c|c|c|c|c|}
\hline & \multicolumn{2}{|c|}{ TRIMARAN } & \multicolumn{3}{|c|}{ TRIGGER } \\
\hline & & $\begin{array}{c}\text { BDP/FF/G } \\
\text { grupè } \\
(\mathbf{n}=576)\end{array}$ & $\begin{array}{l}\text { BDP/FF } \\
\text { grupè } \\
(n=574)\end{array}$ & $\begin{array}{c}\text { BDP/FF/G } \\
\text { grupè } \\
(\mathbf{n}=571)\end{array}$ & $\begin{array}{l}\text { BDP/FF } \\
\text { grupé } \\
(\mathbf{n}=573)\end{array}$ & $\begin{array}{c}\text { BDP/FF ir } \\
\text { tiotropio grupè } \\
(\mathbf{n}=\mathbf{2 8 7})\end{array}$ \\
\hline \multirow[t]{2}{*}{ Lytis, n (proc.) } & Vyrai & $221(38)$ & 221 (39) & $212(37)$ & $245(43)$ & $103(36)$ \\
\hline & Moterys & $355(62)$ & $353(61)$ & $359(63)$ & $328(57)$ & $184(64)$ \\
\hline \multirow[t]{3}{*}{ Rasè, n (proc.) } & Azijiečiai & 0 & 0 & $2(<1)$ & 0 & 0 \\
\hline & Baltieji & $575(100)$ & $574(100)$ & $569(>99)$ & $573(100)$ & $286(>99)$ \\
\hline & Kiti & $1(<1)$ & 0 & 0 & 0 & $1(<1)$ \\
\hline \multicolumn{2}{|l|}{ Amžius, metais } & $52,6(12,4)$ & $52,5(12,2)$ & $53,1(12,2)$ & $54,0(11,9)$ & $51,6(12,3)$ \\
\hline \multirow{2}{*}{$\begin{array}{l}\text { Kūno masès } \\
\text { indeksas, kg/m² }\end{array}$} & $<30, \mathrm{n}$ (proc.) & $28,0(4,81)$ & $27,9(5,07)$ & $28,4(5,14)$ & $28,7(5,87)$ & $28,5(5,21)$ \\
\hline & $\geq 30, \mathrm{n}$ (proc.) & $173(30)$ & $170(30)$ & $204(36)$ & $205(36)$ & $102(36)$ \\
\hline \multirow[t]{3}{*}{ Rūkymas } & Buvę rūkoriai, n (proc.) & $92(16)$ & $76(13)$ & $83(15)$ & $80(14)$ & $42(15)$ \\
\hline & Nerūkantys, n (proc.) & $484(84)$ & $498(87)$ & $488(85)$ & $493(86)$ & $245(85)$ \\
\hline & Rūkymo istorija, pakmečiai & $4,1(2,4)$ & $4,8(2,5)$ & $4,9(2,4)$ & $4,8(2,3)$ & $5,6(2,6)$ \\
\hline \multicolumn{2}{|c|}{ Astmos trukmè, metais } & $24,8(12,9)$ & $25,2(12,8)$ & $24,8(12,2)$ & $26,2(12,6)$ & $24,5(12,4)$ \\
\hline \multirow{2}{*}{$\begin{array}{l}\text { Paūmèjimai per } \\
\text { pastaruosius } \\
\text { metus, n (proc.) }\end{array}$} & 1 & $474(82)$ & $473(82)$ & $439(77)$ & $452(79)$ & $229(80)$ \\
\hline & $>1$ & $102(18)$ & $101(18)$ & $132(23)$ & $121(21)$ & $58(20)$ \\
\hline \multicolumn{2}{|c|}{ Prieš salbutamolį FEV ${ }_{1}, \mathrm{I}$} & $1,7(0,56)$ & $1,7(0,56)$ & $1,6(0,56)$ & $1,6(0,57)$ & $1,6(0,59)$ \\
\hline \multicolumn{2}{|c|}{ Prieš salbutamolį FEV ${ }_{1}$, proc. būtinojo dydžio } & $55,2(12,3)$ & $55,7(12,0)$ & $51,9(13,5)$ & $51,8(13,5)$ & $52,1(13,2)$ \\
\hline \multicolumn{2}{|l|}{ Grįžtamumas, proc. } & $32,5(24,72)$ & $30,8(20,53)$ & $33,2(20,21)$ & $33,9(21,87)$ & $34,9(26,99)$ \\
\hline \multicolumn{2}{|c|}{ Prieš salbutamoli FEV $/$ FVC santykis } & $0,60(0,12)$ & $0,61(0,12)$ & $0,59(0,12)$ & $0,59(0,13)$ & $0,59(0,12)$ \\
\hline \multicolumn{2}{|c|}{ Po salbutamolio $\mathrm{FEV}_{1} / \mathrm{FVC}$ santykis } & $0,65(0,11)$ & $0,65(0,11)$ & $0,63(0,12)$ & $0,63(0,12)$ & $0,63(0,12)$ \\
\hline \multirow{3}{*}{$\begin{array}{l}\text { Prieš tyrimą varto- } \\
\text { tas gydymas IGK } \\
\text { arba IVBA, } n \text { (proc.) }\end{array}$} & IGK & $61(11)$ & $72(13)$ & $153(27)$ & $144(25)$ & $67(23)$ \\
\hline & IGK/IVBA & $531(92)$ & $515(90)$ & $525(92)$ & $520(91)$ & $267(93)$ \\
\hline & IVBA & $55(10)$ & $66(11)$ & $74(13)$ & $71(12)$ & $35(12)$ \\
\hline \multicolumn{2}{|l|}{ ACQ-7 skalè, balais } & $2,3(0,52)$ & $2,3(0,53)$ & $2,5(0,53)$ & $2,4(0,54)$ & $2,4(0,53)$ \\
\hline \multirow[t]{2}{*}{$\mathrm{PEF}, \mathrm{I} / \mathrm{min}$. } & Ryte & $297(107,5)$ & $299(106,0)$ & $279(104,2)$ & $275(101,2)$ & $287(106,4)$ \\
\hline & Vakare & $310(108,2)$ & $314(107,6)$ & $292(104,7)$ & $287(103,1)$ & $299(107,6)$ \\
\hline \multicolumn{2}{|c|}{ Kasdienių astmos simptomų skalè, balais } & $0,76(0,49)$ & $0,77(0,50)$ & $0,81(0,52)$ & $0,83(0,51)$ & $0,84(0,50)$ \\
\hline \multicolumn{2}{|c|}{ Dienos be astmos simptomu, proc. } & 9,9 & 11,0 & 10,2 & 9,5 & 10,8 \\
\hline \multicolumn{2}{|c|}{ Dienos, kai astma buvo kontroliuojama, proc. } & 9,1 & 10,4 & 9,9 & 8,9 & 10,1 \\
\hline
\end{tabular}

Duomenys pateikiami n (proc.), vidurkiu (SN) arba intervalas. TRIMARAN - trigubos terapija sergantiesiems nekontroliuojama astma ir gydomiems vidutinèmis IGK dozèmis bei IVBA tyrimas (angl. Triple in Asthma With Uncontrolled Patients on Medium Strength of ICS + LABA study); TRIGGER - triguba dideliu IGK dozių terapija sergantiesiems astma, lyginant su gydymu didelių dozių IGK/IVBA ir tiotropiu tyrimas (angl.Triple in Asthma High Strength Versus ICS/ LABA HS and Tiotropium study).

ACQ-7 - Astmos kontrolès klausimynas-7 (angl. Asthma Control Questionnaire-7); BDP - beklometazono dipropionatas; FEV 1 - forsuoto iškvèpimo tūris per 1 sek. (angl. forced expiratory volume in 1 second); FF - formoterolio fumaratas; FVC - forsuota gyvybinè talpa (angl. forced vital capacity); G - glikopironis; IGK - jkvepiamieji gliukokortikoidai; IVBA - ilgo veikimo $\beta$-2 agonistas; PEF - didžiausia iškvèpimo srovè (angl. peak expiratory flow). 


\section{Farmakoterapija}

A
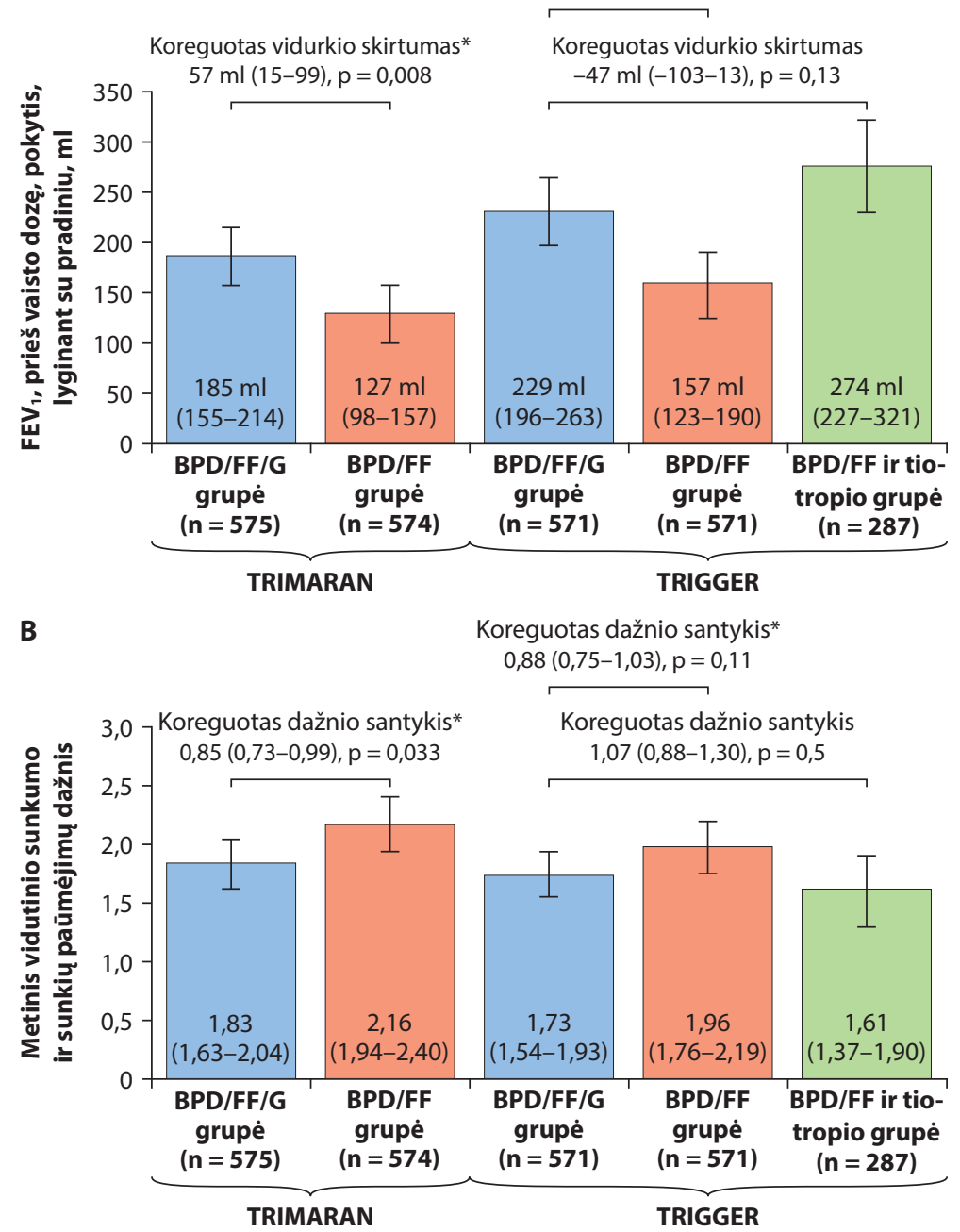

1 pav. TRIMARAN ir TRIGGER tyrimų pirminès vertinamosios baigtys

(A) FEV 1 prieš vaisto dozę pokytis 26 gydymo savaitę, lyginant su pradiniu. (B) Metinis vidutinio sunkumo ir sunkiu paūmejjimy dažnis. TRIMARAN (angl. Triple in Asthma With Uncontrolled Patients on Medium Strength of ICS $+\angle A B A)$ - triguba terapija sergantiesiems nekontroliuojma astma ir gydomiems vidutinemis IGK dozèmis bei IVBA; TRIGGER (angl. Triple in Asthma High Strength Versus ICS/LABA HS and Tiotropium) - triguba terapija skiriant dideles IGK dozes sergantiesiems astma, palyginus su gydymu didelemis IGK dozèmis, IVBA ir tiotropiu. BDP beklometazono dipropionatas; FF - formoterolio fumaratas; $\mathrm{G}$ - glikopironis; $\mathrm{FEV}_{1}$ - forsuoto iškvèpimo tūris per 1 sek.

$\mathrm{p}=0,0080$ ), o TRIGGER tyrime $-73 \mathrm{ml}$ (95 proc. PI $26-120 ; \mathrm{p}=0,0025)$ (1A pav.). TRIGGER tyrime $\mathrm{FEV}_{1}$ prieš vaisto dozę po 26 gydymo savaičių nesiskyrè tarp $\mathrm{BDP} / \mathrm{FF} / \mathrm{G}$ bei $\mathrm{BDP} / \mathrm{FF}$ ir tiotropio grupių $(-45 \mathrm{ml}$, -103 iki $13 ; \mathrm{p}=0,13)$. TRIMARAN tyrime vidutinio sunkumo ir sunkių paūmejjimų dažnis reikšmingai (15 proc.) sumažèjo BDP/FF/G grupeje, lyginant su $\mathrm{BDP} / \mathrm{FF}$ grupe (SR $0,85,95$ proc. PI $0,73-0,99 ; \mathrm{p}=$ 0,033; 1B pav.). TRIGGER tyrime paūmèjimai sumažèjo 12 proc., tačiau šis sumažejimas nebuvo nereikšmingas $(0,88,95$ proc. PI $0,75-1,03 ; \mathrm{p}=0,11)$. Taip pat TRIGGER tyrime nenustatyta paūméjimų dažnio skirtumo tarp BDP/FF/G grupes ir BDP/FF ir tiotropio grupès $(1,07,95$ proc. PI $0,88-1,30 ; \mathrm{p}=0,50$ ) (1B pav.).

Pagrindinès antrinès vertinamosios baigtys: verti- nant didžiausią $\mathrm{FEV}_{1} 26$ gydymo savaitę ir vidutini rytini PEF per 26 gydymo savaites, pokytis, lyginant su pradiniu, buvo didesnis $\mathrm{BDP} / \mathrm{FF} / \mathrm{G}$ grupeje, lyginant su $\mathrm{BDP} / \mathrm{FF}$ grupe abiejuose tyrimuose (didžiausiam $\mathrm{FEV}_{1} \mathrm{p}=0,0002$ ir vidutiniam rytiniam PEF $\mathrm{p}=0,0006$ TRIMARAN tyrime bei didžiausiam $\mathrm{FEV}_{1} \mathrm{p}<0,0001$ ir vidutiniam rytiniam PEF $\mathrm{p}=0,0014$ TRIGGER tyrime). Tačiau TRIGGER tyrime nenustatyta reikšmingo skirtumo tarp BDP/FF/G grupes ir BDP/FF su tiotropiu grupès (didžiausiam $\mathrm{FEV}_{1} \mathrm{p}=0,27$ ir vidutiniam rytiniam PEF $p=0,95 ; 2 A$ ir 2B pav.). Vertinant bendrus abiejų tyrimu duomenis, pacientai gydyti BDP/FF/G grupeje patyrè reikšmingai mažiau sunkių paūmèjimų, lyginant su $\mathrm{BDP} / \mathrm{FF}$ grupès pacientais ( 23 proc.; $\mathrm{p}=00076 ; 2 \mathrm{C}$ pav.).

TRIGGER tyrime nenustatyta kliniškai reikšmingo skirtumo tarp BDP/FF/G ir $\mathrm{BDP} / \mathrm{FF}$ grupių arba BDP/FF plius tiotropis grupès, vertinant ACQ-7 bendrą balu skaičių arba atsaką bei skubiosios pagalbos medikamentų vartojimą. Tačiau pažymètina, kad abiejų tyrimų metu, lyginant su tyrimų pradžia, pagerėjo astmos simptomai, astmos kontrolè ir sumažèjo skubiosios pagalbos medikamentu vartojimas visose penkiose tyrimų grupèse.

Bendrai nepageidaujamų poveikių proporcingai vienodai nustatyta visose penkiose tyrimų grupèse. Daugelis nepageidaujamų poveikiu buvo lengvi ar vidutinio sunkumo, keletas buvo susije su gydymu. Dažniausias nepageidaujamas poveikis visose grupèse buvo astmos paūmejjimas, tačiau jis buvo retesnis trigubos terapijos grupeje nei BDP/FF grupeje abiejuose tyrimuose. Keturiems pacientams nustatyti sunkūs su gydymu susiję nepageidaujami poveikiai: prieširdžių virpejimas TRIMARAN tyrimo BDP/ FF/G grupeje, stemplès kandidozè TRIGGER tyrimo $\mathrm{BDP} / \mathrm{FF} / \mathrm{G}$ grupejje, pneumonija bei glaukoma TRIGGER tyrimo BDP/FF grupejje. Dèl visų šių sunkių su gydymu susijusių nepageidaujami poveikių gydymo keisti nereikèjo.

\section{APTARIMAS}

TRIMARAN ir TRIGGER yra pirmieji tyrimai, įvertinę itin smulkių dalelių trigubos terapijos viename inhaliatoriuje veiksmingumą ir saugumą gydant sergančiuosius astma. Plaučiu funkcijos pagèrèjimas $\left(\mathrm{FEV}_{1}\right.$, vertinant prieš vaisto dozę) kaip pirminis tyrimo tikslas buvo pasiektas abiejose tyrimuose. Nežymiai didesnis 
plaučių funkcijos pagerèjimas nustatytas TRIGGER tyrime. Kitas pirminis tyrimo tikslas - vidutinio sunkumo ir sunkių astmos paūmèjimų dažnio sumažèjimas pasiektas tik TRIMARAN tyrime. Šiame tyrime reikšmingai 15 proc. sumažejo paūmèjimų dažnis BDP/FF/G gydytų pacientu grupeje, lyginant su BDP/FF grupe. Panašus poveikis užfiksuotas ir TRIGGER tyrime, astmos paūmejjimų dažnis sumažèjo 12 proc., tačiau šis pokytis buvo statistiškai nereikšmingas. Siekiant pagrindinio antrinio tyrimo tikslo, analizuoti bendrieji abiejų tyrimų duomenys parodė, kad BDP/ FF/G net 23 proc. sumažina sunkių astmos paūmèjimų dažnị. Bendra abiejų tyrimų duomenų analizè, siekiant su paūmèjimais susijusių tikslų, parodé, kad BDP/FF/G 12 proc. sumažina vidutinio sunkumo paūmèjimų dažnị ir 14 proc. bendrai vidutinio sunkumo ir sunkių paūmèjimų dažnị. Laikas iki pirmo vidutinio sunkumo arba sunkaus astmos paūmejjimo, gydant BDP/ $\mathrm{FF} / \mathrm{G}$, buvo ilgesnis, nei gydant BDP/FF Visi šie paūméjimų duomenys rodo, kad nekontroliuojamos astmos gydymas BDP/ FF/G labiau apsaugo nuo paūméjimų nei gydymas BDP/FF.

Vertinti klinikinę TRIMARAN ir TRIGGER tyrimų rezultatų reikšmę pakankamai sudetinga, nes analizuojamas pridètinio gydymo veiksmingumas, ji pridedant prie jau žinomo veiksmingo astmos gydymo IGK/IVBA. Nustatytas skirtumas tarp $\mathrm{BDP} / \mathrm{FF} / \mathrm{G}$ ir BDP/FF grupių, vertinant pvz., kvėpavimo funkciją, skaitmenine išraiška yra labai nežymus ir tai rodo tik vidutinị trigubos terapijos veiksmingumą. Tačiau šiame tyrime dalyvavusių pacientų populiacija turi mažai pridètinio gydymo pasirinkimo galimybių, todèl netgi vidutinis pagèrejimas gali būti vertingas Taip pat šie tyrimai parodè, kad bet kuris grupès gydymas yra gerai toleruojamas ir pridetas ilgo veikimo muskarino antagonistas nepadidina nepageidaujamų poveikių dažnio. Pasaulineje astmos iniciatyvoje (angl. The Global Initiative for Asthma, GINA) jau yra rekomendacija apie ilgo veikimo muskarino antagonistus, kurią, kaip pridetinę terapiją, patartina vartoti pacientams, kurių astma nèra kontroliuojama gydant ikvepiamaisiais IGK ir IVBA. Itin smulkių dalelių BDP/ $\mathrm{FF} / \mathrm{G}$ derinys viename inhaliatoriuje turè-

\section{A}

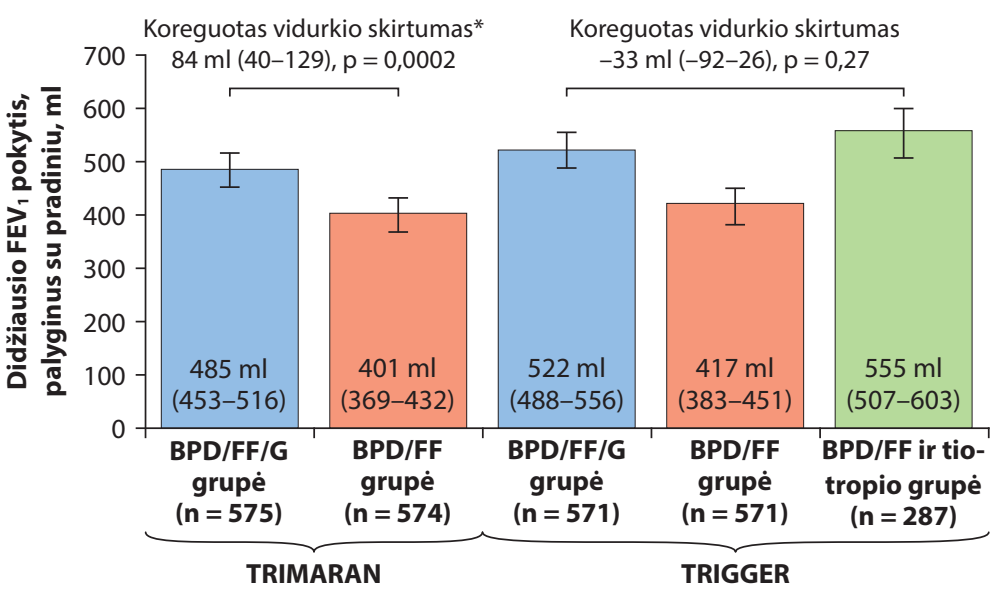

B
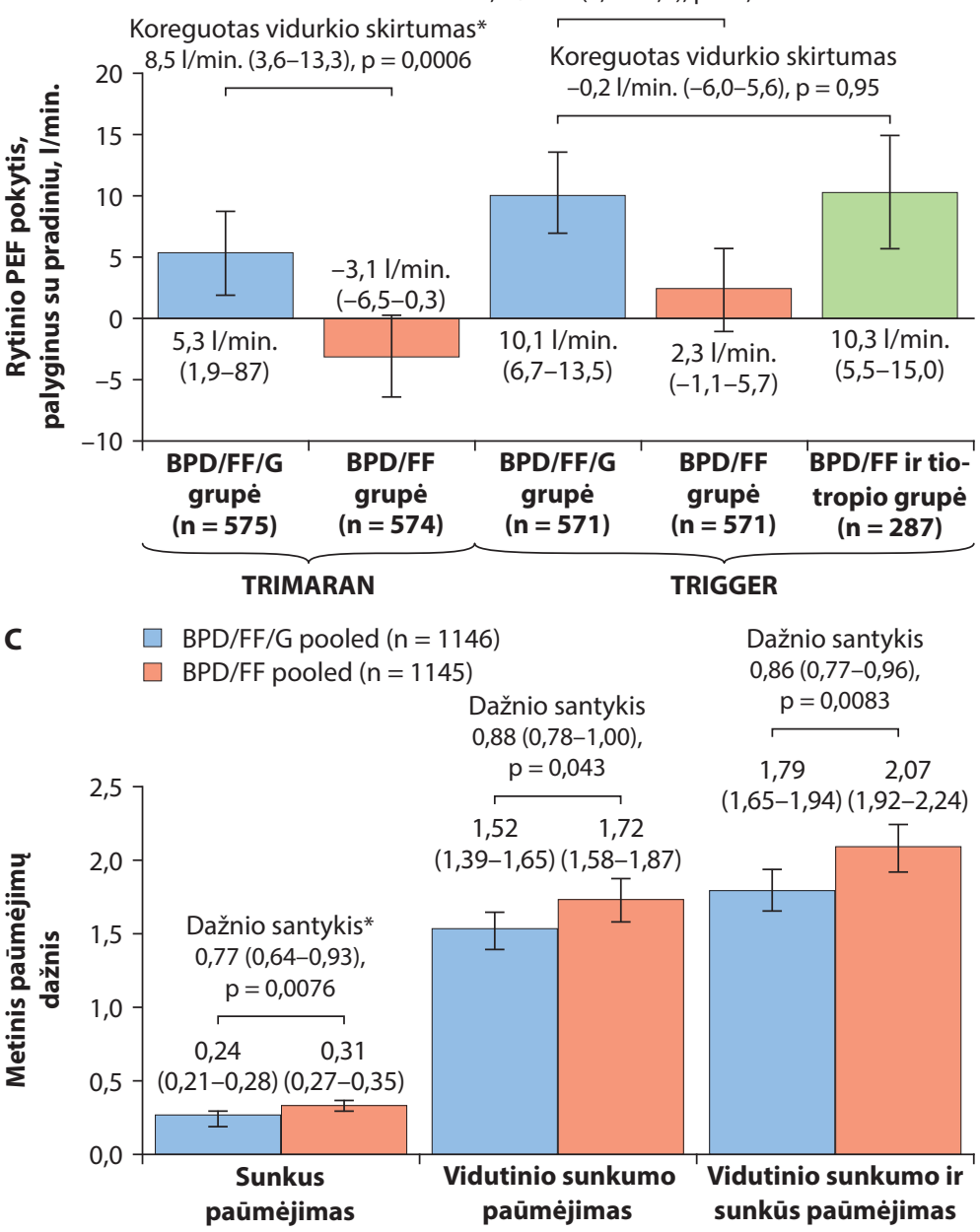

2 pav. TRIMARAN ir TRIGGER tyrimų pagrindinès antrinès vertinamosios baigtys

(A) Didžiausias FEV 1 pokytis 26 savaitę, palyginus su pradiniu. (B) Vidutinis rytinès PEF pokytis 26 sav., palyginus su pradiniu. (C) Metinis sunkiu, vidutinio sunkumo ir vidutinio sunkumo ir sunkių kartu paūmèjimų dažnis (bendra abiejų tyrimų duomenų analizè). TRIMARAN (angl. Triple in Asthma With Uncontrolled Patients on Medium Strength of ICS + LABA) - triguba terapija sergantiesiems nekontroliuojma astma ir gydomiems vidutinėmis IGK dozėmis bei IVBA; TRIGGER (angl. Triple in Asthma High Strength Versus ICS/LABA HS and Tiotropium) - triguba terapija skiriant dideles IGK dozes sergantiesiems astma, palyginus su gydymu didelemis IGK dozemis, IVBA ir tiotropiu. BDP - beklometazono dipropionatas; FF - formoterolio fumaratas; $\mathrm{G}$ - glikopironis; $F_{E V}$ - forsuoto iškvèpimo tūris per 1 sek.; PEF - didžiausia iškvèpimo srovè. 


\section{Farmakoterapija}

tų būti patrauklus pasirinkimas tiek pacientams, tiek sveikatos priežiūros specialistams.

\section{APIBENDRINIMAS}

TRIMARAN ir TRIGGER tyrimų rezultatai parodè, kad sergantiesiems nekontroliuojama astma ir gydomiems vidutinėmis-didelèmis ịkvepiamųjų gliukokortikoidų dozemis ir ilgo veikimo $\beta_{2}$ agonistais, pridejus ilgo veikimo muskarino antagonistą ir skiriant itin smulkių dalelių trigubą terapiją $\mathrm{BDP} / \mathrm{FF} / \mathrm{G}$ viename inhaliatoriuje, pagerèja kvèpavimo funkcija, taip pat toks gydymas susijęs su teigiamu poveikiu mažinant sunkių astmos paūmèjimų dažnį, astmos simptomus ir siekiant astmos kontrolès.

Parengta pagal straipsni Virchow J, Kuna $P, P a-$ ggiaro P, Papi A, Singh D, Corre S, et al. Single inhaler extrafine triple therapy in uncontrolled asthma (TRIMARAN and TRIGGER): two double-blind, parallel-group, randomised, controlled phase 3 trials. Lancet. 2019;394(10210):1737-49.

\section{LITERATŪRA}

1. Reddel HK, FitzGerald JM, Bateman ED, Bacharier LB, Becker A, Brusselle G et al.. GINA 2019: a fundamental change in asthma management: treatment of asthma with short acting bronchodilators alone is no longer recom- mended for adults and adolescents. Eur Respir J. 2019; 53: 1901046

2. Hirst C, Calingaert B, Stanford R, Castellsague J. Use of long acting $\beta$ agonists and inhaled steroids in asthma: metaanalysis of observational studies. J Asthma. 2010; 47:439-46.

3. Kerstjens HA, Engel M, Dahl R, Paggiaro P, Beck E, Vandewalker M. Tiotropium in asthma poorly controlled with standard combination therapy. N Engl J Med. 2012; 367:1198-207.

4. Ohta $K$, Ichinose $M$, Tohda $Y$, Engel M, Moroni-Zentgraf $P$, Kunimitsu S, et al. Long term once daily tiotropium respimat is well tolerated and maintains efficacy over 52 weeks in patients with symptomatic asthma in Japan: a randomised, placebo controlled study. PLoS One. 2015; 10: e0124109.

5. Hoshino M, Ohtawa J, Akitsu K. Effects of the addition of tiotropium on airway dimensions in symptomatic asthma. Allergy Asthma Proc. 2016; 37:147-53.

6. Delea TE, Hagiwara M, Stanford RH, Stempel D. Effects of fluticasone propionate/salmeterol combination on asthma related health care resource utilization and costs and adherence in children and adults with asthma. Clin Ther. 2008; 30:560-71.

7. Marceau C, Lemière C, Berbiche D, Perreault S, Blais L. Persistence, adherence, and effectiveness of combination therapy among adult patients with asthma. J Allergy Clin Immunol. 2006; 118:574-81.

8. Stoloff SW, Stempel DA, Meyer J, Stanford RH, Carranza Rosenzweig JR. Improved refill persistence with fluticasone propionate and salmeterol in a single inhaler compared with other controller therapies. J Allergy Clin Immunol. 2004; 113: 245-51.

9. Stempel DA, Stoloff SW, Carranza Rosenzweig JR, Stanford RH, Ryskina KL, Legorreta AP. Adherence to asthma controller medication regimens. Respir Med. 2005; 99:1263-67.

10. Lipworth B, Manoharan A, Anderson W. Unlocking the quiet zone: the small airway asthma phenotype. Lancet Respir Med. 2014; 2: 497-506. 